\title{
Erratum to: Genetic isolation of Korean populations of Apodemus peninsulae (Rodentia: Muridae) from their neighboring populations
}

\author{
Hye Ri Kim ${ }^{1}$ Yung Chul Park ${ }^{1}$
}

Published online: 19 November 2015

(C) The Genetics Society of Korea and Springer-Science and Media 2015

In the above paper, the Acknowledgement should be corrected as follows:

This work was carried out with support of Cooperative Research Program for Agricultural Science \&
Technology Development (Project No. PJ01085902), Rural Development Administration, Republic of Korea.

The online version of the original article can be found under doi: 10.1007/s13258-015-0331-0.

Yung Chul Park

parky@kangwon.ac.kr

1 College of Forest and Environmental Science, Kangwon

National University, Chuncheon 200-701, Republic of Korea 